\title{
Ultrathin Ni-MOF Nanobelts-Derived Composite for High Sensitive Detection of Nitrite
}

\author{
Xiangren Meng ${ }^{1,2 * t}$, Xiao Xiao ${ }^{3 t}$ and Huan Pang ${ }^{3 *}$ \\ ${ }^{1}$ School of Tourism and Culinary Science, Yangzhou University, Yangzhou, China, ${ }^{2}$ Jiangsu Huai-yang Cuisine Engineering \\ Center, Yangzhou University, Yangzhou, China, ${ }^{3}$ School of Chemistry and Chemical Engineering, Yangzhou University, \\ Yangzhou, China
}

OPEN ACCESS

Edited by:

Baiqing Yuan,

Ludong University, China

Reviewed by:

Guoxing Zhu,

Jiangsu University, China

Sujuan $L i$,

Anyang Normal University, China

*Correspondence:

Xiangren Meng

xrmeng@yzu.edu.cn

Huan Pang

huanpangchem@hotmail.com;

panghuan@yzu.edu.cn

tThese authors have contributed equally to this work

Specialty section:

This article was submitted to

Supramolecular Chemistry,

a section of the journal

Frontiers in Chemistry

Received: 15 February 2020

Accepted: 31 March 2020

Published: 23 April 2020

Citation:

Meng $X$, Xiao $X$ and Pang $H$ (2020)

Ultrathin Ni-MOF Nanobelts-Derived

Composite for High Sensitive

Detection of Nitrite.

Front. Chem. 8:330.

doi: 10.3389/fchem.2020.00330
In this paper, the $\mathrm{Ni} / \mathrm{NiO}$ ultrathin nanobelts were successively synthesized by a facile in suit conversion process using pre-synthesized Ni-based metal-organic frameworks (MOFs) nanobelts as parent materials to detect the nitrite $\left(\mathrm{NaNO}_{2}\right)$. The synthesized $\mathrm{Ni} / \mathrm{NiO}$ composites have the advantages in structure, as follows: (I) Interleaved 3D reticulated structure has strong mechanical stability; (II) Ultrathin nanobelt structures allow more active sites to be exposed and make the transfer of charge faster; (III) A large number of ultrafine $\mathrm{Ni}$ nanoparticles decorate the building blocks of the $\mathrm{NiO}$ nanobelt and enhance the electrical conductivity. Ni/NiO/GCE has an obvious oxidation peak at $0.78 \mathrm{~V}$, when the concentration is between 0.5 and $1000 \mu \mathrm{M}$, the oxidation peak current of $\mathrm{NaNO}_{2}$ is linearly related to the concentration, and the sensitivity is $1.5319 \mu \mathrm{A} \mathrm{mM}^{-1}$ $\mathrm{cm}^{-2}(\mathrm{~S} / \mathrm{N}=3)$. Moreover, the experimental results also concluded that the $\mathrm{Ni} / \mathrm{NiO}$ ultrathin nanobelts not only indicated wonderful reproducibility in the determination of $\mathrm{NaNO}_{2}$ in the pickled pork samples, but also could be well-recovered and keep stable for a long time.

Keywords: in suit conversion method, $\mathrm{Ni} / \mathrm{NiO}$ ultrathin nanobelt, metal nanoparticle, metal organic framework, nitrite

\section{INTRODUCTION}

Metal-organic frameworks (MOFs) are expected to play a significant role in energy applications (Lin et al., 2015; Xia et al., 2015; Tan et al., 2017; Liang et al., 2018; Wu et al., 2019; Yang et al., 2019; Zhao Y. et al., 2019). Because the micro/nanoscale structure has a great potential to overcome the disadvantages of low specific surface area (SSAs) and poor contacts of active materials with electrolyte/pollutants compared to conventional bulks or aggregate materials. Therefore, it is considered as a promising electrode material (Du et al., 2014, 2017; Bosch et al., 2017; Chen et al., 2017; Shi et al., 2017; Li Y.-P. et al., 2019; Xiao et al., 2020). In recent years, since it has been noted that various processes such as thermodynamics and kinetics of various reactions occurring at the interface are significantly affected by the surface energy of micro/nanocrystals, MOF-derived materials have become a research hotspot (Yang et al., 2008; Larsson et al., 2009; Du et al., 2014, 2017; Bosch et al., 2017; Chen et al., 2017; Shi et al., 2017; Liu et al., 2019; Li Y.-P. et al., 2019; Xiao et al., 2020). Many studies have focused on designing and controlling their different morphologies. On the basis of keeping the original geometry of the micro/nanostructure unchanged, the derivatization can improve the low conductivity and enhance the structural stability of the original MOFs (Chen et al., 2012; Liu et al., 2014; Ma et al., 2017; Shi et al., 2017; Wang et al., 2018; Zou et al., 2018). 
Because of its great importance in catalysis, metal nanoparticles are rapidly attracting widespread interest (Han et al., 2010; Zhang et al., 2010, 2012, 2014; Xu et al., 2014; Li Q. Y. et al., 2019; Zhu et al., 2019). However, the high surface energy of metal nanoparticles makes them thermodynamically unstable during the process of catalytic reaction, and it is easy to aggregate, resulting in reduced activity. Therefore, whether the size, shape and dispersion of metal nanoparticles can be controlled properly is the key factor to determine whether the stability activity can be improved. To the end, small metal nanoparticles with specific shapes are generally prepared from many surface capping agents including dendrimers, oleamide, and polyethylenepyrrolidone (PVP) (Cho et al., 2016; Zhao et al., 2016; Li et al., 2018; Zhang et al., 2019; Zhao R. B. et al., 2019). Although this surface capping agent is considered effective, in most cases, it is not ideal to attach molecules to metal nanoparticles with strong chemical interactions and inhibit the catalytic reaction. In order to produce surface-clean and well-dispersed metal nanoparticles, limiting them within porous materials, such as porous silica, zeolites, as well as porous carbons are currently common methods. Through the porous materials, the pore-responsive substrates/products can be transferred, porous materials can also avoid the aggregation and growth of metal nanoparticles, all of which are attributed to its inherent conditions for spatial confinement (Zhan and Zeng, 2016, 2018; Chen and Xu, 2017; Xu et al., 2017; Li et al., 2018; Geng et al., 2019). MOFs and MOF-derived materials can stand out among numerous porous materials and become excellent choices because (1) they have diverse pore sizes and shapes to meet the special requirements of metal nanoparticles; (2) They have high porosity and specific surface areas to carry metal nanoparticles; (3) Understanding catalysis requires defining the MOF structure distinctly and ensuring that the pore structure is easily tailored in order to assure that the surrounding environment of metal nanoparticles is easily identified (Mukoyoshi et al., 2015; Tang et al., 2018; Chen et al., 2019; Li Y.-P. et al., 2019).

Nitrite, mainly sodium nitrite $\left(\mathrm{NaNO}_{2}\right)$, is often used as a preservative and a food additive in daily life. The high content of nitrite in the human body not only causes hemoglobin to be irreversibly oxidized to high-iron hemoglobin, but also reacts with dietary components to produce nitrosamines, leading to cancer and high blood pressure (Yue et al., 2011; Lin Z. et al., 2015). Therefore, eating meat products, sauces and spoiled vegetables with higher levels of nitrate or nitrite, or the drinking water containing nitrate or nitrite can cause poisoning (Li et al., 2012; Zou et al., 2017). In this work, we report that, with presynthesized ultrathin Ni-MIL-77 nanobelts as parent materials, a facile in situ conversion way $\left(\mathrm{O}_{2}\right.$-protected annealing process) has been demonstrated to fabricate metal nickel nanoparticle functionalized $\mathrm{NiO}$ composites ( $\mathrm{Ni} / \mathrm{NiO}$ ultrathin nanobelts). An excellent electrochemical performance of the $\mathrm{Ni} / \mathrm{NiO}$ ultrathin nanobelts with large surface area and metal $\mathrm{Ni}$ nanoparticles generated by in situ conversion method is exhibited during the oxidation of $\mathrm{NaNO}_{2}$. In addition, $\mathrm{NaNO}_{2}$ in pickled pork was determined by the $\mathrm{Ni} / \mathrm{NiO}$ materials, and good recovery was achieved.

\section{RESULTS AND DISCUSSION}

\section{Synthesis Strategy}

In this work, we used Ni-MIL-77 as the precursor because it presented a chiral structure that has large cross channels (Figure $\mathrm{S1}$ ). The $\mathrm{Ni} / \mathrm{NiO}$ composite reported here was made by using an in suit conversion process. Two steps are included in the preparation of $\mathrm{Ni}$-functionalized $\mathrm{NiO}$ ultrathin nanobelts (Figure 1A). In step I, we successfully synthesized Ni-MIL-77 ultrathin nanobelts under solvothermal conditions (Xiao et al., $2017,2018,2019)$. In step II, we used a method that anneals the nickel-based ultrathin nanobelts in air at an elevated temperature to make it converted into $\mathrm{Ni} / \mathrm{NiO}$ heterostructure nanobelts in situ. There are many structural features of the obtained $\mathrm{Ni} / \mathrm{NiO}$ composite (Figure 1B): (I) interleaved 3D reticulated structure has strong mechanical stabilities; (II) More active sites are exposed and the charge transfer process is also promoted due to ultrathin nanobelt structures; (III) A large number of ultrafine $\mathrm{Ni}$ nanoparticles decorate the building blocks of the $\mathrm{NiO}$ nanobelt and enhance the electrical conductivity.

\section{Characterizations of $\mathrm{Ni} / \mathrm{NiO}$ Heterostructure}

The thermogravimetric (TG) curve of Ni-MIL-77 that shows two obvious weight losses is given in Figure S2. In the temperature range of 25 to $100^{\circ} \mathrm{C}$ is the first step of the weight loss (a $6 \%$ drop), which is equivalent to the decrease of the adsorbed solvent molecules. While the temperature reaches $400^{\circ} \mathrm{C}$, since the Ni-MIL-77 skeleton is decomposed and glutaric acid $\left(\mathrm{HOOC}\left(\mathrm{CH}_{2}\right)_{3} \mathrm{COOH}\right)$ ligands turn into gas, weight loses $40.1 \%$. Therefore, we can obtain $\mathrm{Ni} / \mathrm{NiO}$ heterostructures at $350^{\circ} \mathrm{C}$.

The morphology of the samples can be observed using transmission electron microscopy (TEM) and field emission scanning electron microscopy (FESEM). The typical lowmagnification SEM images in Figure S3 and TEM images in Figure $\mathrm{S} 4$ show that the morphology of $\mathrm{Ni}-\mathrm{MOF}$ and $\mathrm{Ni} / \mathrm{NiO}$ composites are ultrathin nanobelts. The results show that the thickness of $\mathrm{Ni} / \mathrm{NiO}$ nanobelts is about $3 \mathrm{~nm}$ (Figure S5). Further understanding of the architecture of the $\mathrm{Ni} / \mathrm{NiO}$ composites is shown in Figure 2. It can be clearly seen from Figures 2a,b that the $\mathrm{Ni}$ metal nanoparticles have been in situ generate. These small metal particles are uniformly distributed on the $\mathrm{NiO}$-based surface, forming a stable $\mathrm{Ni} / \mathrm{NiO}$ composite (Figure $2 \mathrm{c}$ ). The rational elemental constituents (e.g., $\mathrm{Ni}$, and $\mathrm{O}$ ) of the product is shown in the energy-dispersive $\mathrm{X}$-ray spectrum (EDX)mapping without impurities in $\mathrm{Ni} / \mathrm{NiO}$ ultrathin nanobelts (Figures 2d-g).

We used XRD to test the phase purity as well as the crystallographic structure of the experimental product. By calcining Ni-MIL-77 at $350^{\circ} \mathrm{C}$, we found two kinds of diffraction peaks ( $\mathrm{Ni}$ and $\mathrm{NiO}$ ) in the Figure $2 \mathbf{i}$ and Figure S6. Five welldefined diffraction peaks at 37.248, 43.286, 62.852, 75.404, and 79.372 are assigned to the (101), (012), (110), (113), and (202) facets of $\mathrm{NiO}$, respectively. And three well-defined diffraction peaks at $44.507,51.846$, and 76.370 are distributed to the (111), (200), and (220) facets of Ni, respectively. The diffraction peaks 

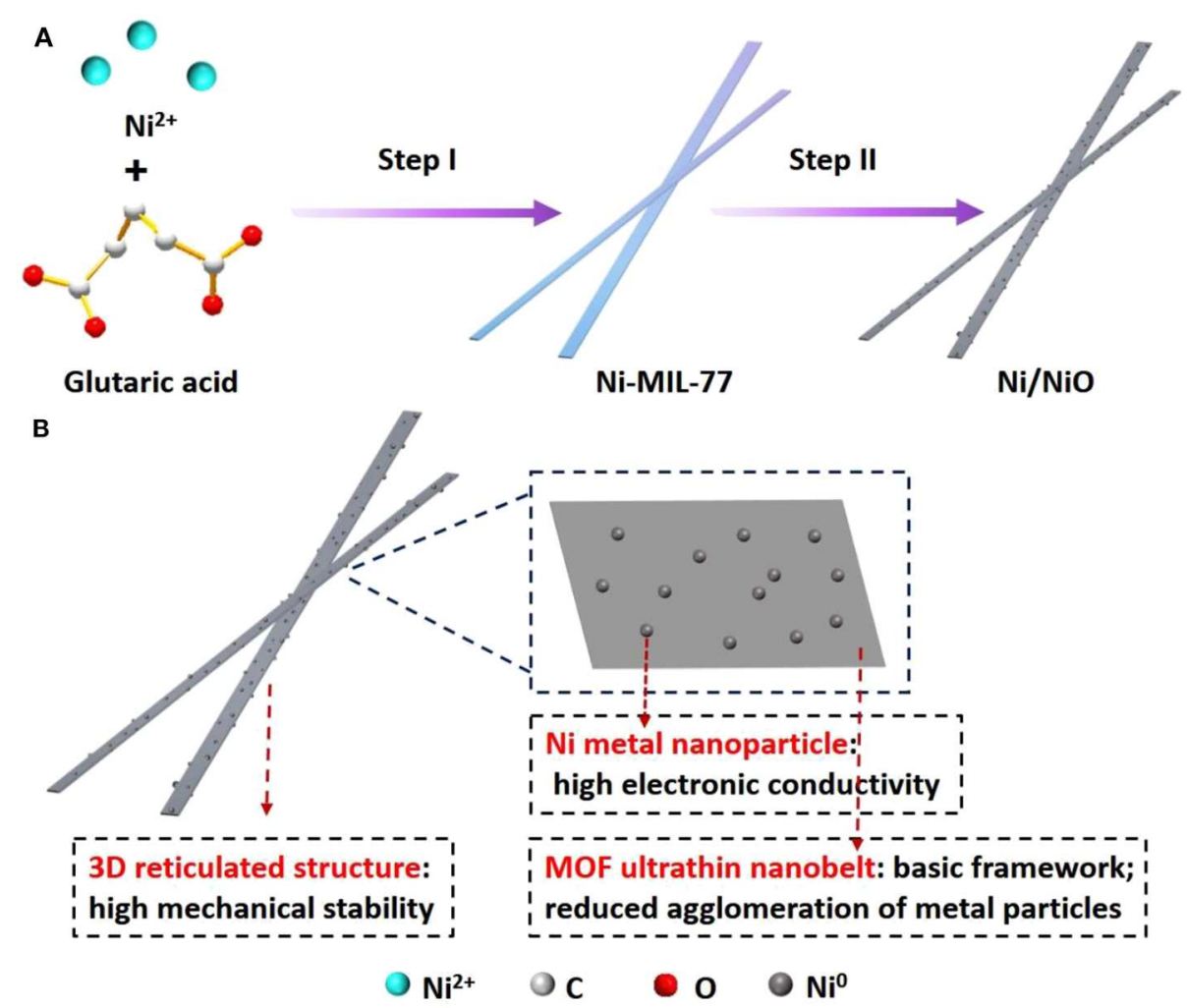

FIGURE 1 | (A) Schematic illustration of the synthesis of Ni/NiO ultrathin nanobelts. Step I: hydrothermal treatment of Ni-MIL-77 ultrathin nanobelts; Step II: annealing the Ni-MOF ultrathin nanobelts in air. (B) Schematic illustration of the detailed Ni/NiO ultrathin nanobelts.

can be easily assigned to the standard NiO phase (JCPDS 441159) as well as Ni phase (JCPDS 04-0850) (Tang et al., 2018; Zhao L. et al., 2019).

An effective method that can distinguish functional groups in the products is X-ray photoelectron spectroscopy (XPS). Figure 3 shows the XPS spectra of Ni-MOF nanobelts and $\mathrm{Ni} / \mathrm{NiO}$ nanobelts and their survey spectra. The survey spectra (Figure 3A) show three apparent peaks at 282.63 (C 1s), 530.29 (O 1s), and 856.37 ( $\mathrm{Ni} 2 \mathrm{p}$ ), respectively, which implied that Ni-MIL-77 nanobelts and $\mathrm{Ni} / \mathrm{NiO}$ nanobelts were successfully formed. Ni oxidation states are determined through performing $\mathrm{Ni} 2 \mathrm{p}$ XPS spectrum. Two peaks in the $\mathrm{Ni} 2 \mathrm{p}$ region of the XPS spectra for Ni-MIL-77 that centered at $856.1\left(2 \mathrm{p}_{3 / 2}\right)$ and $873.8\left(2 \mathrm{p}_{1 / 2}\right)$ eV corresponded to the $\mathrm{Ni}^{2+}$ ions in Ni-MIL-77 (Figure 3B). In addition to these peaks, a new pair of spin-orbit splitting peaks is generated at $852.8\left(2 \mathrm{p}_{3 / 2}\right)$ and $870.0 \mathrm{eV}\left(2 \mathrm{p}_{1 / 2}\right)$ (Figure $3 \mathrm{C}$ ), corresponding to the formation of $\mathrm{Ni}$ nanoparticles, and the results are consistent with PXRD. Figures S7a, S8a shows the high-resolution XPS spectrum of $\mathrm{C} 1 \mathrm{~s}$, and it can be deconvoluted well into two surface carbon components at $\approx 284.3 \mathrm{eV}$ (nonoxygenated carbon: C-C), as well as $288.1 \mathrm{eV}$ (carboxyl carbon: $\mathrm{O}=\mathrm{C}-\mathrm{O}$ ). Figures $\mathbf{S 7 b}, \mathbf{S} 8 \mathbf{b}$ shows the highresolution XPS spectrum of $\mathrm{O} 1 \mathrm{~s}$.

\section{Determination of $\mathrm{NaNO}_{2}$ on the $\mathrm{Ni} / \mathrm{NiO} / \mathrm{GCE}$}

Figure S9 showed the cyclic voltammograms (CVs) of different electrodes (Ni-MOF/GCE, Ni/NiO/GCE) in $5.0 \mathrm{mM} \mathrm{K}_{3} \mathrm{Fe}(\mathrm{CN})_{6}$ containing $1 \mathrm{M} \mathrm{KCl}$ solution at a scan rate of $50 \mathrm{mV} \mathrm{s}^{-1}$. As displayed in Figure S9, the $\mathrm{Ni} / \mathrm{NiO} / \mathrm{GCE}$ exhibited an increase in the anodic peak current $(192.66 \mu \mathrm{A})$ compared to Ni-MIL77/GCE (108.23 $\mu \mathrm{A})$.

We know that studying the effect of scanning rate on the peak current and oxidation peak potential can be used to judge electrode reaction kinetics. Figure 4 and Figure $\mathbf{S 1 0}$ represented at different scan rates $\left(20-200 \mathrm{mV} \mathrm{s}^{-1}\right)$, the $\mathrm{CVs}$ of $\mathrm{Ni} / \mathrm{NiO} / \mathrm{GCE}$ and Ni-MIL-77/GCE in 0.1 M PBS solution with $5 \mathrm{mM} \mathrm{NaNO}_{2}$, respectively. The anodic peak currents for $\mathrm{Ni} / \mathrm{NiO} / \mathrm{GCE}$ increase linearly with the scan rate as well as the calibration equation is $\mathrm{I}_{\mathrm{pa}}$ $(\mu \mathrm{A})=0.046465 v\left(\mathrm{mV} \mathrm{s}^{-1}\right)+1.35653\left(R^{2}=0.948\right)($ Figure $4 \mathrm{~B})$. This property indicates that the electron transfer for $\mathrm{NaNO}_{2}$ at $\mathrm{Ni} / \mathrm{NiO} / \mathrm{GCE}$ is controlled by an adsorption process. Moreover, it can be seen that the redox peak potential changes slightly with the increase of scan rate, and the linear regression equation of $\mathrm{E}_{\mathrm{pa}}$ and $\log$ of scan rate in Figure $4 \mathrm{C}$ is represented by $\mathrm{E}_{\mathrm{pa}}$ $=0.04951 \lg v+0.69305\left(R^{2}=0.993\right)$. The electron transfer number $(\mathrm{n})$ is calculated according to the Laviron's equation (Yang et al., 2014, 2015). It was found by calculation that there 


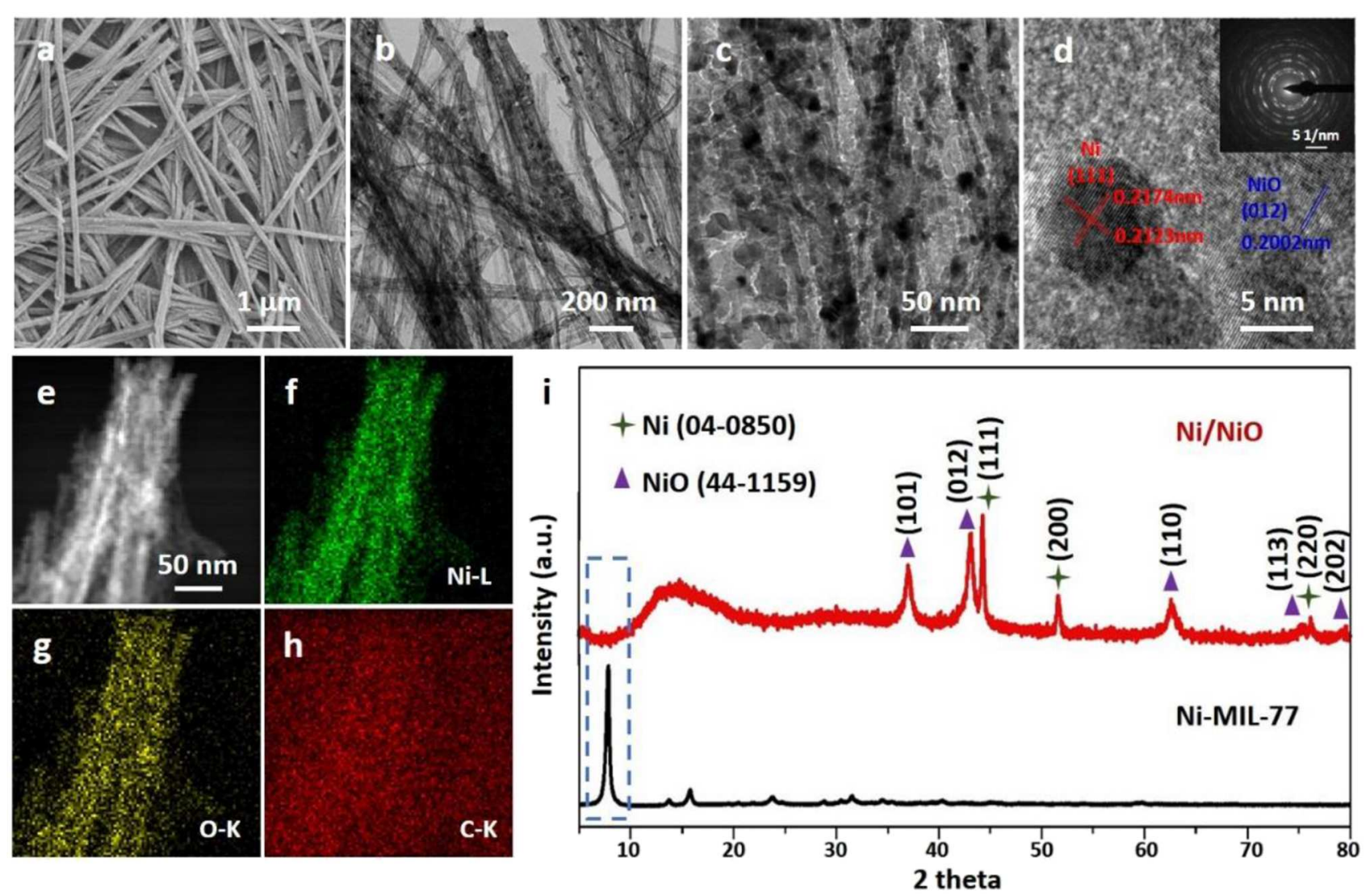

FIGURE 2 | Morphology and structure characterization of Ni/NiO ultrathin nanobelts. (a) SEM, (b,c) TEM, (d) HRTEM (insert: SAED patterns) and (e-h) elemental mapping images of Ni/NiO ultrathin nanobelts. (i) XRD patterns of the Ni-MIL-77 and Ni/NiO.
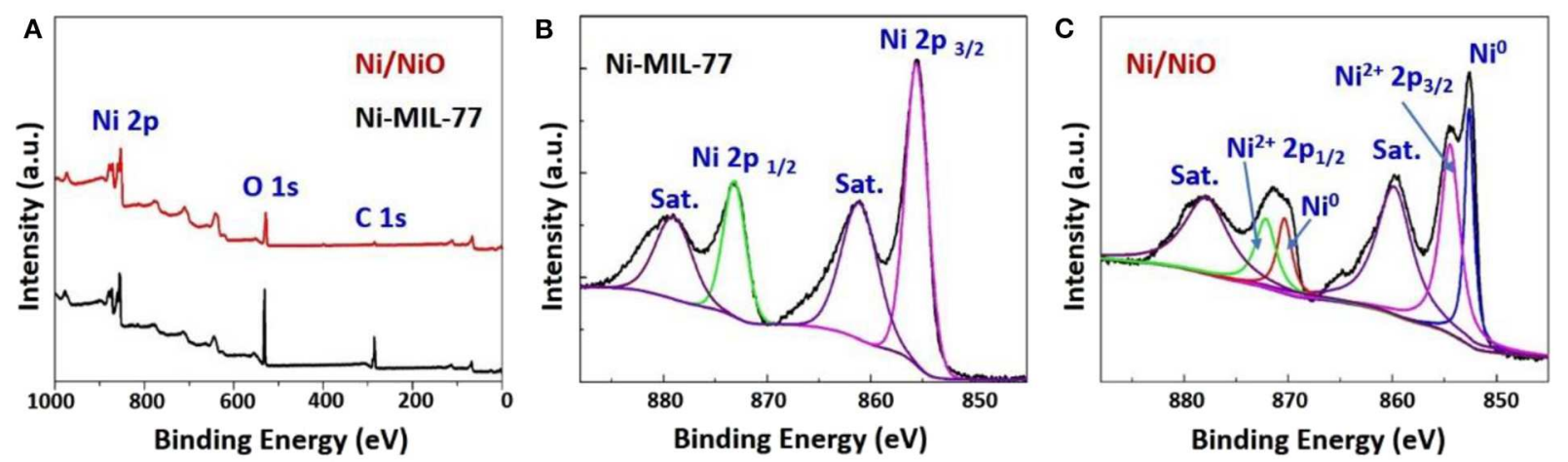

FIGURE 3 | (A) XPS survey of the Ni-MOF and Ni/NiO; Ni 2 $\mathrm{p}_{3 / 2}$ XPS spectra of (B) Ni-MOF (C) and Ni/NiO.

are $2 \mathrm{e}^{-}$involved in the irreversible reaction of $\mathrm{NaNO}_{2}$, and it is consistent with Equation.

$$
\mathrm{NO}_{2}^{-}+\mathrm{H}_{2} \mathrm{O} \rightarrow \mathrm{NO}_{3}^{-}+2 \mathrm{H}^{+}+2 e^{-}
$$

Figures S11, S12 describe the effect of $\mathrm{pH}$ on the response of $5 \mathrm{mM} \mathrm{NaNO} 2 \mathrm{CVs}$ with a $\mathrm{pH}$ range of 4.0-8.0 (scanning rate of $50 \mathrm{mV} \mathrm{s}^{-1}$ ). As seen from Figure S11a, the peak anode current reaches its maximum at $\mathrm{pH}$ 7.0. As reported by Brylev et al. (2007) $\mathrm{N}_{2} \mathrm{O}$ generation may lead to a decrease in peak current at low $\mathrm{pH}$ values. In addition, the oxidation peak of $\mathrm{NaNO}_{2}$ shifted in a very negative direction as $\mathrm{pH}$ increases, so we chose $\mathrm{pH} 7.0$ as the optimal $\mathrm{pH}$ for our experiment.

The linear working range of $\mathrm{Ni} / \mathrm{NiO} / \mathrm{GCE}$ was determined by recording the amperometric response as a function of $\mathrm{NaNO}_{2}$ concentration. Figure 5A shows the typical current time curve of the modified $\mathrm{Ni} / \mathrm{NiO}$ nanobelt electrode and $\mathrm{NaNO}_{2}$ 

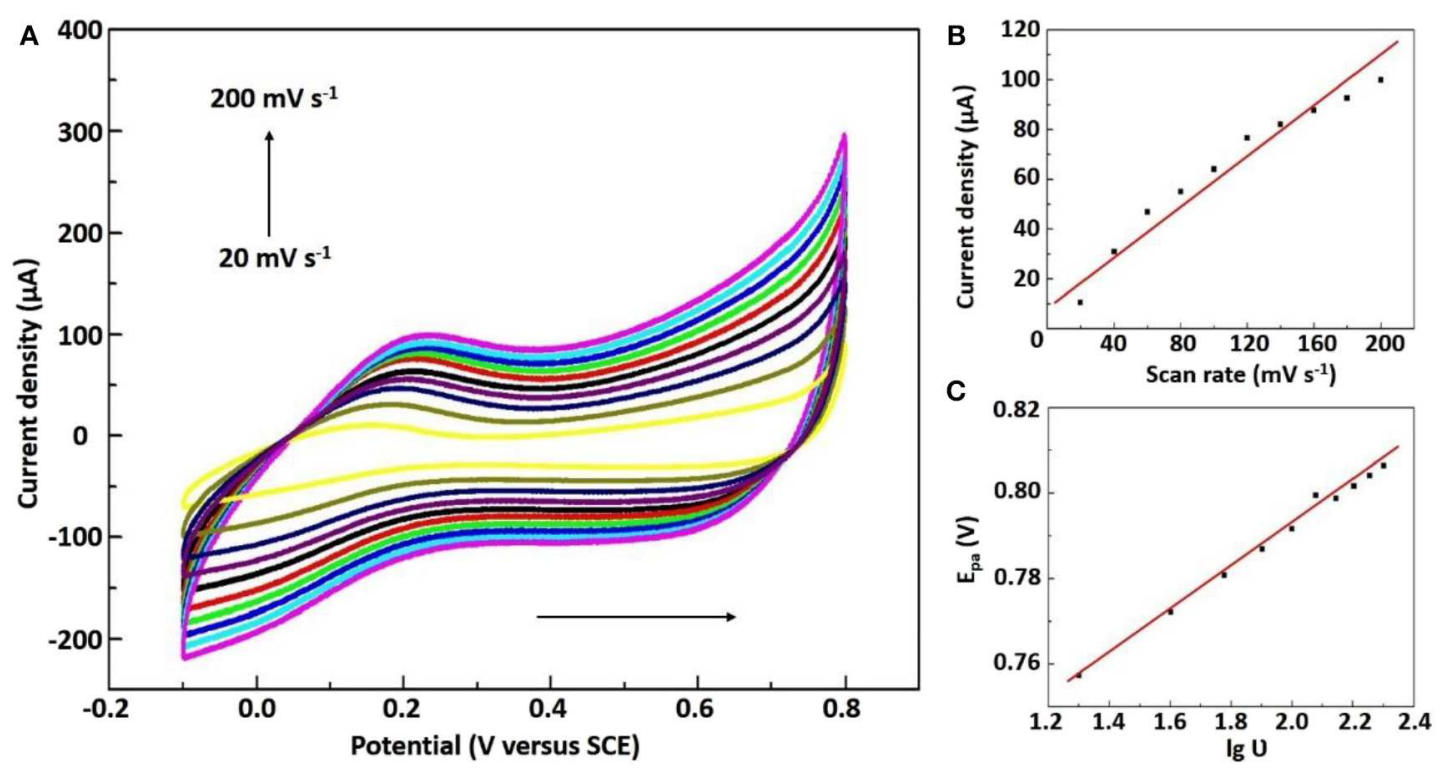

FIGURE 4 | (A) CVs of the Ni/NiO/GCE in 0.1 M PBS solution containing $5 \mathrm{mM} \mathrm{NaNO}_{2}$ (20 to $\left.200 \mathrm{mV} \mathrm{s}^{-1}\right)$. (B) The plots of scan rates to the anodic peak currents. (C) $\lg v$ vs. anodic peak potentials.

solution with continuous injection concentrations from $0.5 \mu \mathrm{M}$ to $1,000 \mu \mathrm{M}$. An obvious reaction occurs when $\mathrm{NaNO}_{2}$ solution concentration is as low as $0.5 \mu \mathrm{M}$. Figure $5 \mathrm{~B}$ exhibits that $\mathrm{Ni} / \mathrm{NiO} / \mathrm{GCE}$ electrode displays a sensitive increase in current response after successive increments of $\mathrm{NaNO}_{2}$ in $0.1 \mathrm{M}$ PBS $(\mathrm{pH}=7)$ solution. After each increase of $\mathrm{NaNO}_{2}$, the current response increases sensitively and rapidly, which shows a nice linear dependence. Two linear working ranges can be seen from Figure 5B. Notably, from the plots of electrocatalytic current versus $\mathrm{NaNO}_{2}$ concentration in the range of $2-100 \mathrm{mM}$ (Figure 5B), the simulated linear equation of the $\mathrm{Ni} / \mathrm{NiO} / \mathrm{GCE}$ is found to be: $\mathrm{I}(m A)=0.117 \mathrm{C}(m M)+0.25324, \mathrm{R}=$ 0.9982 , and the calculated sensitivity is $1.5420 \mathrm{~mA} \mathrm{mM}^{-1} \mathrm{~cm}^{-2}$. The illustrations in Figure 5B shows a good linear response in the range of $2.0 \sim 10.0 \mathrm{mM} \mathrm{NaNO}_{2}$ with a relation coefficient of 0.99926 .

In the complex biological environments, the ability to identify target molecules and interference molecules is very important for sensors. Therefore, we further investigated the effects of some electroactive substances on the $\mathrm{Ni} / \mathrm{NiO} / \mathrm{GCE}$ electrode response. Figure 5C shows the amperometric response of the sensor to the consecutive addition of $\mathrm{NaNO}_{2}, \mathrm{KNO}_{3}, \mathrm{NaSO}_{4}, \mathrm{NaClO}_{4}$, and $\mathrm{KCl}$ to the solution. Only the current response of $\mathrm{NaNO}_{2}$ is remarkable. These results show that GCE modified by $\mathrm{Ni} / \mathrm{NiO}$ ultrathin nanoribends can be used for selective and sensitive detection of $\mathrm{NaNO}_{2}$ without interference from $\mathrm{KNO}_{3}, \mathrm{NaSO}_{4}$, $\mathrm{NaClO}_{4}$ and $\mathrm{KCl}$.

In addition, the stability of the $\mathrm{Ni} / \mathrm{NiO} / \mathrm{GCE}$ electrode was tested. The amperometric response to determining stability is shown in Figure 5D. The result exhibits that $96.72 \%$ of the current response remained unchanged for a long period of $5 \mathrm{~h}$, indicating good stability in the measurement process. As shown in Figure S13, Ni-MIL-77 also exhibits good stability over a long period of $5 \mathrm{~h}$, and a current response of $96.51 \%$ remains unchanged. In order to further appraise the properties of the $\mathrm{Ni} / \mathrm{NiO} / \mathrm{GCE}$, a correlative reference is shown in Table $\mathbf{S} \mathbf{1}$.

The advantages of $\mathrm{Ni} / \mathrm{NiO}$ composites can be summarized as follows:

(1) The study shows that the standard electrode potential decreases $\sim 100 \mathrm{mV}$ when the electrode material size is $1 \mathrm{~nm}$. Therefore, the ultrathin nanobelt structure not only allows more active sites to be exposed, but also promotes charge transfer.

(2) MOF derivative support can effectively avoid agglomeration of ultrafine Ni nanoparticles, and ultrafine Ni nanoparticles can effectively improve the conductivity of MOF materials.

(3) Interleaved 3D reticulated structure has strong mechanical stability.

\section{Determination of $\mathrm{NaNO}_{2}$ in Real Samples}

To illustrate the feasibility and application potential of the electrode, the $\mathrm{Ni} / \mathrm{NiO} / \mathrm{GCE}$ was applied to determine $\mathrm{NaNO}_{2}$ from pickled pork using the standard addition technique. The collected pickled pork was disposed and the spiked $\mathrm{NaNO}_{2}$ concentrations were 10,20 , and $30 \mathrm{mg} \mathrm{kg}^{-1}$, respectively. As shown in Table 1, the recovery rates were 98.3, 100.3, and 99.5\%, respectively. The results show that the method has good recovery rates and good practical value.

\section{CONCLUSIONS}

In summary, $\mathrm{Ni} / \mathrm{NiO}$ ultrathin nanobelts were prepared by a facile in suit conversion method $\left(\mathrm{O}_{2}\right.$-protected annealing 

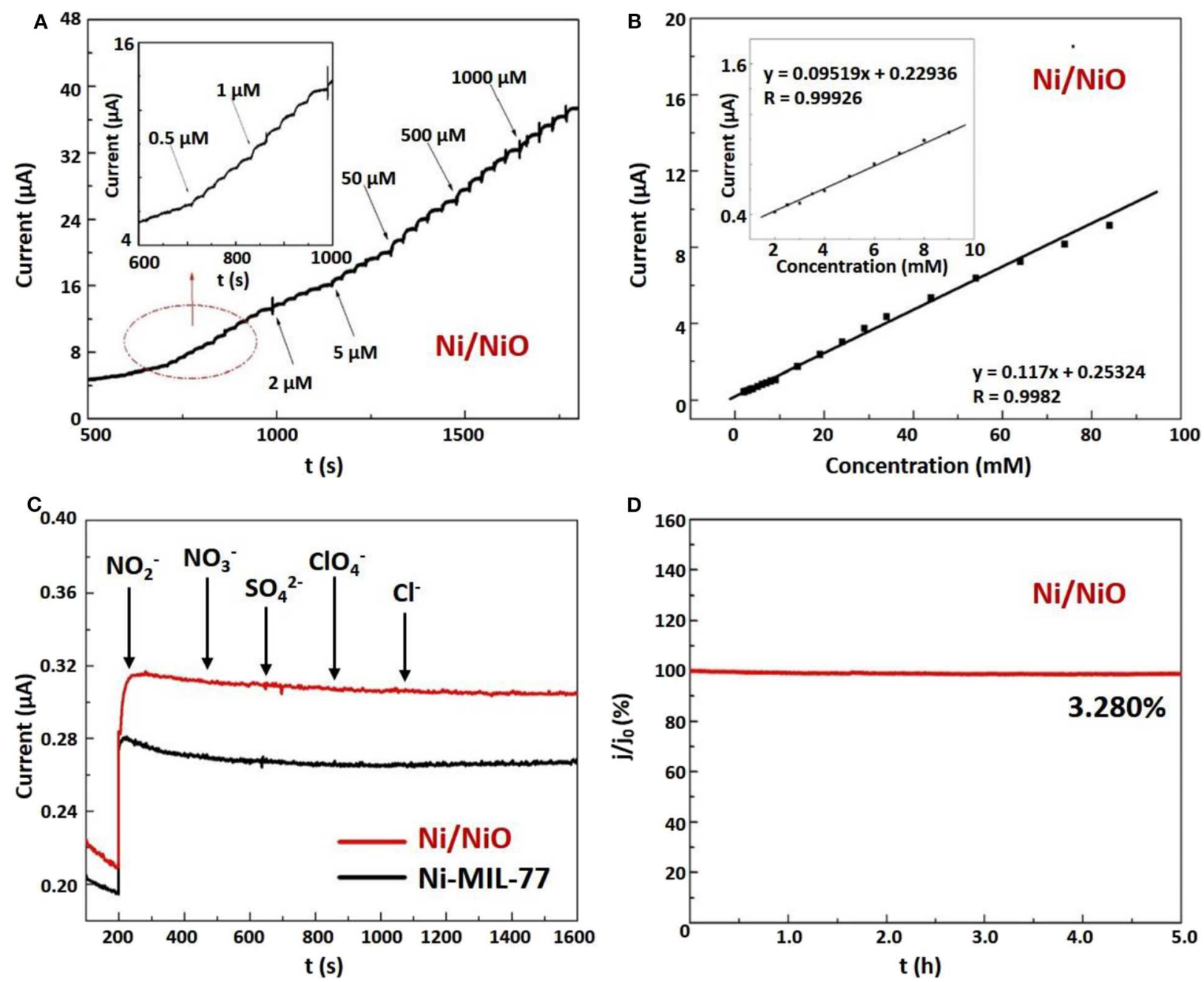

FIGURE 5 | Electrochemical performances of the Ni/NiO ultrathin nanobelts modified electrode. (A) Amperometric responses of the Ni/NiO/GCE electrode to the successive injection of $\mathrm{NaNO}_{2}$ in $0.1 \mathrm{M} \mathrm{PBS}$ (inset: carefully observe the response currents of several micromolar $\mathrm{NaNO}_{2}$ ). (B) The calibration curve of current vs. $\mathrm{NaNO}_{2}$ concentration of 2 100 mM. Inset: calibration curve with $\mathrm{NaNO}_{2}$ concentration of $2 \sim 10 \mathrm{mM}$. (C) Amperometric response of $\mathrm{Ni} / \mathrm{NiO} / \mathrm{GCE}$ to $\mathrm{NO}-$ in the presence of $\mathrm{NO}_{2}^{-}, \mathrm{NO}_{3}^{-}, \mathrm{SO}_{4}^{-}, \mathrm{ClO}_{4}^{-}, \mathrm{Cl}^{-}$. (D) Stability of Ni/NiO/GCE over $5 \mathrm{~h}$.

TABLE 1 | Determination of various concentrations of nitrite in pickled pork.

\begin{tabular}{lccccc}
\hline Samples & $\begin{array}{c}\text { Content } \\
\left(\mathbf{m g ~ k g}^{-\mathbf{1}}\right)\end{array}$ & $\begin{array}{c}\text { Added } \\
\left(\mathbf{m g ~ k g} \mathbf{~}^{-\mathbf{1}}\right)\end{array}$ & $\begin{array}{c}\text { Found } \\
\left(\mathbf{m g ~ k g}^{-\mathbf{1}} \mathbf{)}\right.\end{array}$ & $\begin{array}{c}\text { Recovery } \\
\mathbf{( \% )}\end{array}$ & $\begin{array}{c}\text { R.S.D (\%, } \\
\mathbf{n = 1 0})\end{array}$ \\
\hline 1 & 10.2 & 15 & 24.8 & 98.3 & 2.8 \\
2 & 10.2 & 25 & 35.3 & 100.3 & 2.6 \\
3 & 10.2 & 35 & 45.0 & 99.5 & 3.2 \\
\hline
\end{tabular}

process). The ultrathin nanobelts with large surface area and in situ generated metal $\mathrm{Ni}$ particles exhibit outstanding electrochemical performance. During the oxidation of $\mathrm{NaNO}_{2}$, the $\mathrm{Ni} / \mathrm{NiO}$ ultrathin nanobelts exhibit excellent stability, special reproducibility, and strong anti-interference ability. Moreover, $\mathrm{Ni} / \mathrm{NiO}$ composites also obtained a good recovery rate when it was applied to the determination of $\mathrm{NaNO}_{2}$ in marinated pork. Compared with other methods, the electrochemical method is inexpensive, simple, which is suitable for practical applications.

\section{DATA AVAILABILITY STATEMENT}

All datasets generated for this study are included in the article/Supplementary Material.

\section{AUTHOR CONTRIBUTIONS}

$\mathrm{XM}$ and $\mathrm{XX}$ conducted all the major experiments, designed the study, and wrote the manuscript. HP provided valuable inputs for the study's development and helped with manuscript writing. All authors agree to be accountable for the content of the work. 


\section{FUNDING}

This work was supported by the National Natural Science Foundation of China (NSFC-U1904215, 21671170, and 21673203), the Top-notch Academic Programs Project of Jiangsu Higher Education Institutions (TAPP), Changjiang scholars program of the ministry of Education (Q2018270), and Program for New Century Excellent Talents of the University in China (NCET-13-0645), the Six Talent Plan (2015-XCL-030), Qinglan Project of Jiangsu, Qinglan Project of Yangzhou University. Project supported by the Natural Science Foundation for Young Scientists of Jiangsu Province, China (Grant nos. BK20190903 and 19KJB430043). Postgraduate Research \& Practice Innovation Program of Jiangsu Province (KYCX19-2100).

\section{REFERENCES}

Bosch, M., Yuan, S., Rutledge, W., and Zhou, H. C. (2017). Stepwise synthesis of metal-organic frameworks. Acc. Chem. Res. 50, 857-865. doi: 10.1021/acs.accounts.6b00457

Brylev, O., Sarrazin, M., Roué, L., and Bélanger, D. (2007). Nitrate and nitrite electrocatalytic reduction on Rh-modified pyrolytic graphite electrodes. Electrochim. Acta 52, 6237-6247. doi: 10.1016/j.electacta.2007.03.072

Chen, D. M., Zhang, N. N., Tian, J. Y., Liu, C. S., and Du, M. (2017). Pore modulation of metal-organic frameworks towards enhanced hydrothermal stability and acetylene uptake via incorporation of different functional brackets. J. Mater. Chem. A 5, 4861-4867. doi: 10.1039/C6TA10785K

Chen, F. F., Shen, K., Chen, J. Y., Yang, X. F., Cui, J., and Li, Y. W. (2019). General immobilization of ultrafine alloyed nanoparticles within metal-organic frameworks with high loadings for advanced synergetic catalysis. ACS Cent. Sci. 5, 176-185. doi: 10.1021/acscentsci.8b00805

Chen, L.-F., and Xu, Q. (2017). Converting MOFs into amination catalysts. Science 358, 304-305. doi: 10.1126/science.aap8004

Chen, M., Wu, B. H., Yang, J., and Zheng, N. F. (2012). Small adsorbateassisted shape control of Pd and Pt nanocrystals. Adv. Mater. 24, 862-879. doi: 10.1002/adma.201104145

Cho, K., Han, S., and Suh, M. P. (2016). Copper-organic framework fabricated with CuS nanoparticles: synthesis, electrical conductivity, and electrocatalytic activities for oxygen reduction reaction. Angew. Chemie Int. Ed. 128, 15527-15531. doi: 10.1002/ange.201607271

Du, M., Chen, M., Yang, X. G., Wen, J., Wang, X., Fang, S. M., et al. (2014). A channel-type mesoporous In(iii)-carboxylate coordination framework with high physicochemical stability for use as an electrode material in supercapacitors. J. Mater. Chem. A 2, 9828-9834. doi: 10.1039/C4TA00963K

Du, T. Y., Zhao, C. Q., ur Rehman, F., Lai, L. M., Li, X. Q., Sun, Y., et al. (2017). In situ multimodality imaging of cancerous cells based on a selective performance of $\mathrm{Fe}^{2+}$-adsorbed zeolitic imidazolate framework-8. Adv. Funct. Mater. 27:1603926. doi: 10.1002/adfm.201603926

Geng, P. B., Cao, S., Guo, X. T., Ding, J. W., Zheng, S. S., Zheng, M. B., et al. (2019). Polypyrrole coated hollow metal-organic framework composites for lithiumsulfur batteries. J. Mater. Chem. A 7, 19465-19470. doi: 10.1039/C9TA05812E

Han, J., Li, L. Y., and Guo, R. (2010). Novel approach to controllable synthesis of gold nanoparticles supported on polyaniline nanofibers. Macromolecules 43, 10636-10644. doi: 10.1021/ma102251e

Larsson, E. M., Langhammer, C., Zoric, I., and Kasemo, B. (2009). Nanoplasmonic probes of catalytic reactions. Science 326, 1091-1094. doi: $10.1126 /$ science. 1176593

Li, F.-L., Shao, Q., Huang, X., and Lang, J.-P. (2018). Nanoscale trimetallic metalorganic frameworks enable efficient oxygen evolution electrocatalysis. Angew. Chemie Int. Ed. 57, 1888-1892. doi: 10.1002/anie.201711376

Li, Q. Y., Zhang, L., Xu, Y. X., Li, Q., Xue, H. G., and Pang, H. (2019). Smart Yolk/Shell ZIF-67@POM hybrids as efficient electrocatalysts for

\section{ACKNOWLEDGMENTS}

The authors acknowledge the Jiangsu Huai-yang Cuisine Engineering Center, Priority Academic Program Development of Jiangsu Higher Education Institutions, and the technical support we received at the Testing Center of Yangzhou University.

\section{SUPPLEMENTARY MATERIAL}

The Supplementary Material for this article can be found online at: https://www.frontiersin.org/articles/10.3389/fchem. 2020.00330/full\#supplementary-material

the oxygen evolution reaction. ACS Sustain. Chem. Eng. 7, 5027-5033. doi: 10.1021/acssuschemeng.8b05744

Li, X.-R., Kong, F.-Y., Liu, J., Liang, T.-M., Xu, J.-J., and Chen, H.-Y. (2012). Synthesis of potassium-modified graphene and its application in nitrite-selective sensing. Adv. Funct. Mater. 22, 1981-1988. doi: 10.1002/adfm.201103025

Li, Y.-P., Wang, Y., Xue, Y.-Y., Li, H.-P., Zhai, Q.-G., Li, S.-N., et al. (2019). Ultramicroporous building units as a path to bi-microporous metal-organic frameworks with high acetylene storage and separation performance. Angew. Chemie Int. Ed. 58, 13590-13595. doi: 10.1002/anie.201908378

Liang, Z. B., Qu, C., Xia, D. G., Zou, R. Q., and Xu, Q. (2018). Atomically dispersed metal sites in MOF-based materials for electrocatalytic and photocatalytic energy conversion. Angew. Chemie Int. Ed. 57, 9604-9633. doi: 10.1002/anie.201800269

Lin, M.-C., Gong, M., Lu, B. G., Wu, Y. P., Wang, D.-Y., Guan, M. Y., et al. (2015). An ultrafast rechargeable aluminium-ion battery. Nature 520, 324-328. doi: $10.1038 /$ nature 14340

Lin, Z., Dou, X. N., Li, H. F., Ma, Y., and Lin, J.-M. (2015). Nitrite sensing based on the carbon dots-enhanced chemiluminescence from peroxynitrous acid and carbonate. Talanta 132, 457-462. doi: 10.1016/j.talanta.2014.09.046

Liu, G., Yang, H. G., Pan, J., Yang, Y. Q., Lu, G. Q. M., and Cheng, H.-M. (2014). Titanium dioxide crystals with tailored facets. Chem. Rev. 114, 9559-9612. doi: $10.1021 / \mathrm{cr} 400621 \mathrm{z}$

Liu, G. Y., Sheng, Y., Ager, J. W., Kraft, M., and Xu, R. (2019). Research advances towards large-scale solar hydrogen production from water. Energy Chem 1:100014. doi: 10.1016/j.enchem.2019.100014

Ma, J. L., Ren, F. Z., Wang, G. X., Xiong, Y., Li, Y. Q., and Wen, J. B. (2017). Electrochemical performance of melt-spinning Al-Mg-Sn based anode alloys. Int. J. Hydrogen Energy 42, 11654-11661. doi: 10.1016/j.ijhydene.2017.02.185

Mukoyoshi, M., Kobayashi, H., Kusada, K., Hayashi, M., Yamada, T., Maesato, M., et al. (2015). Hybrid materials of Ni NP@MOF prepared by a simple synthetic method. Chem. Commun. 51, 12463-12466. doi: 10.1039/C5CC0 4663G

Shi, D., Zheng, R., Sun, M.-J., Cao, X., Sun, C.-X., Cui, C.-J., et al. (2017). Semiconductive copper(I)-organic frameworks for efficient light-driven hydrogen generation without additional photosensitizers and cocatalysts. Angew. Chemie Int. Ed. 56, 14637-14641. doi: 10.1002/anie.201709869

Tan, C. L., Cao, X. H., Wu, X.-J., He, Q. Y., Yang, J., Zhang, X., et al. (2017) Recent advances in ultrathin two-dimensional nanomaterials. Chem. Rev. 117, 6225-6331. doi: 10.1021/acs.chemrev.6b00558

Tang, C. J., Liu, Y. N., Xu, C., Zhu, J. X., Wei, X. J., Zhou, L., et al. (2018). Ultrafine nickel-nanoparticle-enabled $\mathrm{SiO}_{2}$ hierarchical hollow spheres for high-performance lithium storage. Adv. Funct. Mater. 28:1704561. doi: 10.1002/adfm.201704561

Wang, F., Liu, Y., Zhao, Y. F., Wang, Y., Wang, Z. J., Zhang, W. H., et al. (2018). Facile synthesis of two-dimensional porous $\mathrm{MgCo}_{2} \mathrm{O}_{4}$ nanosheets as anode for lithium-ion batteries. Appl. Sci. 8:22. doi: 10.3390/app8010022 
Wu, Y. P., Tian, J. W., Liu, S., Li, B., Zhao, J., Ma, L. F., et al. (2019). Bi-Microporous metal-organic frameworks with cubane $\left[\mathrm{M}_{4}(\mathrm{OH})_{4}\right](\mathrm{M}=\mathrm{Ni}, \mathrm{Co})$ clusters and pore-space partition for electrocatalytic methanol oxidation reaction. Angew. Chemie Int. Ed. 58, 12185-12189. doi: 10.1002/anie.201907136

Xia, W., Mahmood, A., Zou, R. Q., and Xu, Q. (2015). Metal-organic frameworks and their derived nanostructures for electrochemical energy storage and conversion. Energy Environ. Sci. 8, 1837-1866. doi: 10.1039/C5EE00762C

Xiao, X., Li, Q., Yuan, X. Y., Xu, Y. X., Zheng, M. B., and Pang, H. (2018). Ultrathin nanobelts as an excellent bifunctional oxygen catalyst: insight into the subtle changes in structure and synergistic effects of bimetallic metal-organic framework. Small Methods 2:1800240. doi: 10.1002/smtd.201800240

Xiao, X., Zhang, G. X., Yuan, Y. X., Zhang, H. L., Guo, X. T., Liu, Y., et al. (2019). A new strategy for the controllable growth of MOF@PBA architectures. J. Mater. Chem. A 7, 17266-17271. doi: 10.1039/C9TA05409J

Xiao, X., Zheng, S. S., Li, X. R., Zhang, G. X., Guo, X. T., Xue, H. G., et al. (2017). Facile synthesis of ultrathin Ni-MOF nanobelts for high-efficiency determination of glucose in human serum. J. Mater. Chem. B 5, 5234-5239. doi: 10.1039/C7TB00180K

Xiao, X., Zou, L. L., Pang, H., and Xu, Q. (2020). Synthesis of micro/nanoscaled metal-organic frameworks and their direct electrochemical applications. Chem. Soc. Rev. 49, 301-331. doi: 10.1039/C7CS00614D

Xu, G. Y., Nie, P., Dou, H., Ding, B., Li, L. Y., and Zhang, X. G. (2017). Exploring metal organic frameworks for energy storage in batteries and supercapacitors. Mater. Today 20, 191-209. doi: 10.1016/j.mattod.2016.10.003

Xu, Q., Gu, S.-X., Jin, L. Y., Zhou, Y. E., Yang, Z. J., Wang, W., et al. (2014). Graphene/polyaniline/gold nanoparticles nanocomposite for the direct electron transfer of glucose oxidase and glucose biosensing. Sensors Actuators B Chem. 190, 562-569. doi: 10.1016/j.snb.2013.09.049

Yang, B. B., Wang, H. W., Du, J., Fu, Y. Z., Yang, P., and Du, Y. K. (2014). Direct electrodeposition of reduced graphene oxide on carbon fiber electrode for simultaneous determination of ascorbic acid, dopamine and uric acid. Colloids Surf. A Physicochem. Eng. Asp. 456, 146-152. doi: 10.1016/j.colsurfa.2014.05.029

Yang, B. B., Wang, J., Bin, D., Zhu, M. S., Yang, P., and Du, Y. K. (2015). A three dimensional $\mathrm{Pt}$ nanodendrite/graphene/ $\mathrm{MnO}_{2}$ nanoflower modified electrode for the sensitive and selective detection of dopamine. J. Mater. Chem. B 3, 7440-7448. doi: 10.1039/C5TB01031D

Yang, H. G., Sun, C. H., Qiao, S. Z., Zou, J., Liu, G., Smith, S. C., et al. (2008). Anatase $\mathrm{TiO}_{2}$ single crystals with a large percentage of reactive facets. Nature 453, 638-641. doi: 10.1038/nature06964

Yang, X. G., Ma, L. F., and Yan, D. P. (2019). Facile synthesis of 1D organicinorganic perovskite micro-belts with high water stability for sensing and photonic applications. Chem. Sci. 10, 4567-4572. doi: 10.1039/C9SC00162J

Yue, R., Lu, Q., and Zhou, Y. K. (2011). A novel nitrite biosensor based on single-layer graphene nanoplatelet-protein composite film. Biosens. Bioelectron. 26, 4436-4441. doi: 10.1016/j.bios.2011. 04.059

Zhan, G. W., and Zeng, H. C. (2016). Synthesis and functionalization of oriented metal-organic-framework nanosheets: toward a series of $2 \mathrm{D}$ catalysts. Adv. Funct. Mater. 26, 3268-3281. doi: 10.1002/adfm.2015 05380

Zhan, G. W., and Zeng, H. C. (2018). Hydrogen spillover through Matryoshka-type (ZIFs@) $)_{n-1}$ ZIFs nanocubes. Nat. Commun. 9:3778. doi: 10.1038/s41467-018-06269-z
Zhang, S., Zhao, Y. X., Shi, R., Waterhouse, G. I. N., and Zhang, T. R. (2019). Photocatalytic ammonia synthesis: recent progress and future. Energy Chem. 1:100013. doi: $10.1016 /$ j.enchem.2019.100013

Zhang, Y. C., Du, Z. N., Li, S. Y., and Zhang, M. (2010). Novel synthesis and high visible light photocatalytic activity of $\mathrm{SnS} 2$ nanoflakes from $\mathrm{SnCl}_{2} \cdot 2 \mathrm{H}_{2} \mathrm{O}$ and S powders. Appl. Catal. B Environ. 95, 153-159. doi: 10.1016/j.apcatb.2009.12.022

Zhang, Y. C., Li, J., and Xu, H. Y. (2012). One-step in situ solvothermal synthesis of $\mathrm{SnS} 2 / \mathrm{TiO} 2$ nanocomposites with high performance in visible light-driven photocatalytic reduction of aqueous Cr(VI). Appl. Catal. B Environ. 123-124, 18-26. doi: 10.1016/j.apcatb.2012.04.018

Zhang, Y. C., Yao, L., Zhang, G. S., Dionysiou, D. D., Li, J., and Du, X. H. (2014). One-step hydrothermal synthesis of high-performance visible-light-driven $\mathrm{SnS}_{2} / \mathrm{SnO}_{2}$ nanoheterojunction photocatalyst for the reduction of aqueous Cr(VI). Appl. Catal. B Environ. 144, 730-738. doi: 10.1016/j.apcatb.2013.08.006

Zhao, L., Zhang, Y., Zhao, Z. L., Zhang, Q.-H., Huang, L.-B., Gu, L., et al. (2019). Steering elementary steps towards efficient alkaline hydrogen evolution via size-dependent $\mathrm{Ni} / \mathrm{NiO}$ nanoscale heterosurfaces. Natl. Sci. Rev. 7, 27-36. doi: 10.1093/nsr/nwz145

Zhao, R. B., Xie, H. T., Chang, L., Zhang, X. X., Zhu, X. J., Tong, X., et al. (2019). Recent progress in the electrochemical ammonia synthesis under ambient conditions. EnergyChem 1:100011. doi: 10.1016/j.enchem.2019.100011

Zhao, S. L., Wang, Y., Dong, J. C., He, C.-T., Yin, H. J., An, P. F., et al. (2016) Ultrathin metal-organic framework nanosheets for electrocatalytic oxygen evolution. Nat. Energy 1:16184. doi: 10.1038/nenergy.2016.184

Zhao, Y., Wang, Y. J., Wang, N., Zheng, P., Fu, H. R., Han, M. L., et al. (2019). Tetraphenylethylene-decorated metal-organic frameworks as energy-transfer platform for the detection of nitro-antibiotics and whitelight emission. Inorg. Chem. 58, 12700-12706. doi: 10.1021/acs.inorgchem.9b 01588

Zhu, R. M., Ding, J. W., Jin, L., and Pang, H. (2019). Interpenetrated structures appeared in supramolecular cages, MOFs, COFs. Coord. Chem. Rev. 389, 119-140. doi: 10.1016/j.ccr.2019. 03.002

Zou, C. E., Yang, B. B., Bin, D., Wang, J., Li, S. M., Yang, P., et al. (2017). Electrochemical synthesis of gold nanoparticles decorated flower-like graphene for high sensitivity detection of nitrite. J. Colloid Interface Sci. 488, 135-141. doi: 10.1016/j.jcis.2016.10.088

Zou, L. L., Hou, C.-C., Liu, Z., Pang, H., and Xu, Q. (2018). Superlong single-crystal metal-organic framework nanotubes. J. Am. Chem. Soc. 140, 15393-15401. doi: $10.1021 /$ jacs.8b09092

Conflict of Interest: The authors declare that the research was conducted in the absence of any commercial or financial relationships that could be construed as a potential conflict of interest.

The reviewer GZ declared a past co-authorship with one of the authors HP to the handling editor.

Copyright (c) 2020 Meng, Xiao and Pang. This is an open-access article distributed under the terms of the Creative Commons Attribution License (CC BY). The use, distribution or reproduction in other forums is permitted, provided the original author(s) and the copyright owner(s) are credited and that the original publication in this journal is cited, in accordance with accepted academic practice. No use, distribution or reproduction is permitted which does not comply with these terms. 